ORIGINAL ARTICLE

\title{
A new species of phlebotomine sandfly, Pintomyia (Pifanomyia) duckei (Diptera: Psychodidae) from Manaus, State of Amazonas, Brazil
}

\author{
Arley Faria José de OLIVEIRA ${ }^{1}$, Ronildo Baiatone ALENCAR ${ }^{2}$, Rui Alves de FREITAS ${ }^{3}$ \\ Universidade Federal do Amazonas, Programa de Pós-Graduação em Diversidade Biológica - ICB, Av. General Rodrigo Octavio Jordão Ramos, Coroado I, 69.067- \\ 005, Manaus, Amazonas, Brazil. \\ 2 Instituto Nacional de Pesquisas da Amazônia, Coordenação de Biodiversidade, Av. André Araújo, 2936, Petrópolis, 69.067-375, Manaus, Amazonas, Brazil. \\ 3 Instituto Nacional de Pesquisas da Amazônia, Coordenação de Sociedade, Ambiente e Saúde, Av. André Araújo, 2936, Petrópolis, 69.067-375, Manaus, Amazonas, Brazil \\ * E-mail: alencarronildo@gmail.com
}

\section{ABSTRACT}

Pintomyia (Pifanomyia) duckei Oliveira, Alencar and Freitas sp. n. from Adolpho Ducke Reserve, Manaus, Amazonas state, Brazil, is described and illustrated based on three male specimens, the holotype and two paratypes. The paratypes have abnormalities in the external genitalia, one with asymmetric bilateral anomaly (different anomalies in each of certain paired structures) and the other with unilateral anomaly (anomaly in one of the paired structures). The new species probably belongs to the Serrana Series, integrating the list of the species whose males possess gonostylus with two stout spines (one apical and other subapical), as well as a small and very thin spine on the inner surface of the basal half.

KEYWORDS: taxonomy, anomalous sandflies, Ducke Forest Reserve, Serrana Series

\section{Uma nova espécie de flebotomíneo, Pintomyia (Pifanomyia) duckei (Diptera: Psychodidae) de Manaus, Estado do Amazonas, Brasil}

\section{RESUMO}

Pintomyia (Pifanomyia) duckei Oliveira, Alencar e Freitas sp. n. da Reserva Florestal Adolpho Ducke, Manaus, Estado do Amazona, Brasil, é descrita e ilustrada com base em três espécimes machos, o holótipo e dois parátipos. Os parátipos possuem anomalias na genitália externa, sendo um com anomalia bilateral assimétrica (anomalias diferentes em cada uma das estruturas pareadas) e outro com anomalia unilateral (anomalia em uma das estruturas pareadas). A nova espécie provavelmente pertence à Série Serrana, integrando a lista das espécies, cujos machos possuem gonóstilo com dois espinhos robustos (um apical e outro subapical), bem como um espinho delgado e muito curto na superfície interna da metade basal.

PALAVRAS-CHAVE: taxonomia, flebotomíneos anômalos, Reserva Ducke, Série Serrana

\section{INTRODUCTION}

Reviewing the reference collection of sandflies from the leishmaniasis laboratory of the Instituto Nacional de Pesquisas da Amazônia (INPA), established in 1975 by the researcher Jorge Arias, we found three male specimens (one normal and two anomalous) that were identified as belonging to a new phlebotomine taxon, previously identified in the group verrucarum Theodor, 1965. Although the entire collection has been revised, no other specimens, male or female, of this new species were found.

The new taxon is described and illustrated according to the classification proposed by Galati $(2003 ; 2017)$. The least incomplete specimen was chosen as the holotype, which presented the best quality of slide preparation and bilateral symmetry of the morphological structures of taxonomic interest.

\section{MATERIAL AND METHODS}

Phlebotomines were collected in November 1977 and January 1978 in the Adolpho Ducke Forest Reserve, $\mathrm{km} 26$ of the State Highway AM-010 from the cities of Manaus to Itacoatiara, in the state of Amazonas, Brazil (255’51”S; 59 58'30”W). The sandflies were collected with a CDC light trap (Hausherr Machine Works, New Jersey, EUA) (Sudia and Chamberlain, 1962) combined with a 
styrofoam box containing $250 \mathrm{~g}$ of dry ice, allowing only a slow release of $\mathrm{CO}_{2}$. The traps were installed at a height of $15 \mathrm{~m}$ in the forest canopy, and kept in operation from 18:00 h until 06:00 h. The specimens were individually mounted on glass slides, using synthetic Canada balsam, in the best conditions for taxonomic identification. For the specimens described in here, identification, nomenclature and morphology followed Galati $(2003 ; 2017)$ and Galati $e t$ al. (2017). For some morphological structures we adopted the terminology proposed by Cumming and Wood (2009). Abbreviations used for generic and sub-generic categories are in accordance with Marcondes (2007).

The description of the new taxon is based in three male specimens, the holotype and two paratypes. All measurements are in micrometers $(\mu \mathrm{m})$ and are presented for the holotype, followed by the paratypes in parenthesis. Measurements were provided for each evident morphological structure. The specimens were studied and measured using a binocular microscope Olympus (CBA) equiped with a micrometer scale. The illustrations were made with the aid of a drawing tube (Zeiss West Germany 474620 - 9900).

\section{RESULTS}

Pintomyia (Pifanomyia) duckei sp. nov (Figure 1)

Male: Small insect, 1984 (1766 and 1790) in length (thorax + abdomen), generally of medium brown color, subtly contrasting with lighter pleura. Head (Figure 1d): length 316 (316 and 342), from post-occiput to clypeus apex; maximum width 297 (310 and 323); length/width ratio 1.06 (1.02 and 1.06). Normal eyes, length 177 (177 and 190); width 126 (126 and 120). Incomplete interocular suture; diameter of ommatidia 13 (13 and 13); interocular distance 76 (63 and 95), equivalent to 5.8 (4.8 and 7.3) ommatidia diameters. Complete chitinous arch and pigmented spots form a tenuous perpendicular line, irregular, extending to the middle of the clypeus. Unarmed cibarium and pharynx; length 141 (135 and atrophied), with thin striations in the $1 / 4$ distal. Labrumepipharynx length 184 (190 and 193); labial suture joined in furca. Each flagellomere has a pair of simple ascoids, short and approximately at the same level, inserted in the basal limit of the $1 / 3$ distal, not reaching the apex of the respective flagellomere, except in FI, where they are implanted just beyond the half of the structure, with the inner ascoid more basal than the outer ascoid; in the absence of FXIV, the possible antennal formula is: FI-FXI2, FXII1, FXIII0. Palpus length 652 (603 and 671). Length of the palpal segments: PI $=34$ (37 and 34), PII = 104 (104 and 104), PIII = 116 (122 and 126), PIV = 92 (89 and 95), PV = 306 (251 and 312). Palpal formula: 1.4.2.3.5, PV being larger than PI+PII+PIII. Newstead's sensillae scattered on the medial inner face of PIII.

Thorax: length 430 (456 and 448), from the anterior margin of the pronotum to the posterior margin of the metanotum. Color: light brown pronotum, paratergite, mesonotum, metanotum and coxae, contrasting smoothly with clearer pleurae. Presence of ventro $\neg$ cervical sensillae and 2 (2 and 3) proepimeral setae. Anepisternum with 7 (7 and 6) upper setae, and 2 lower setae; presence of pilosity on the frontal margin of the catepisternum. Wing (Figure 1e): length 1329 (1367 and 1348); width 386 (430 and 418), length being about 3.5 times the width. Wing venation: alpha length 234 (278 and 278); beta 202 (177 and 158), gamma 234 (232 and 234); delta 63 (44 and 63), pi 76 (76 and 63), R5 905 (918 and 962), alpha and gamma being of the same length. Legs: lost. Abdomen: length 1554 (1310 and 1342), from first tergite to the gonostylus apex. Terminalia (Figure 1a, Figure 1b, Figure 1c): Gonostylus length 89 (89 and 89), width 38 (38 and 38), with two well developed and thick spines ( 1 apical and 1 subapical external), in addition to a reduced and very thin spine on the inner median face, and presence of subapical spiniform seta. Gonocoxite short and very wide (length less than or equal to twice the width), length 228 (240 and 221), width 120 (114 and 120), with an extensive

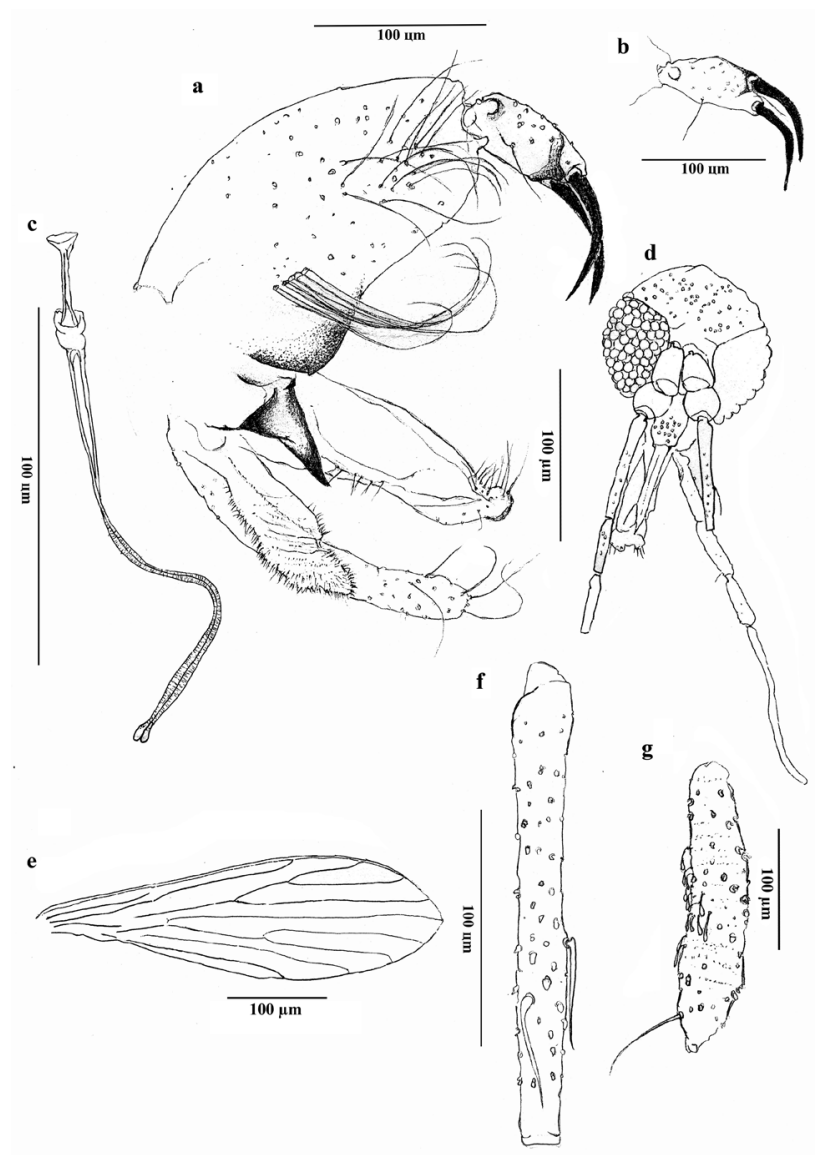

Figure 1. Male holotype of Pintomyia (Pifanomyia) duckei sp. n. Oliveira, Alencar \& Freitas: (a) Terminalia; (b) Gonostylus in lateral position; (c) Sperm pump and ejaculatory ducts; (d) Head frontal view; (e) Wing; (f) Flagellomere l; (g) Palpal segment III. 
and salient sclerosed longitudinal range in the internal basal margin. In the holotype, each gonocoxite has one basal tuft of 5 long setae, slender from the distal half, curved upwardly toward the structure, and arranged in a longitudinal row. In the internal distal $1 / 3$ of the gonocoxite, a diffuse group of 20 or more simple, long and semi-deciduous setae is evident. In the anomalous specimens, some of these characters are altered and will be discussed later. Paramere simple, wide or inflated, with slightly convex dorsal margin, length 272 (285 and 285), width 63 (57 and 63), with narrow preapical. Apex of the paramere (Figure 1a) slender and very short, folded laterally or on the structure, provided with a row of simple and uniform setae, on the dorsal surface. Aedeagus coniform, well sclerosed, with slender apex. Epandrial lobe length 221 (221 and 240), width 32 (32 and 32). Sperm pump length 101 (101 and 98), ejaculatory apodeme (piston) length 76 (76 and 83), ejaculatory ducts length 410 (407 and 410), striated in the distal half, with dilated apexes, filaments about 4 times the length of the pump (Figure 1c); cercus subtriangular.

Female: unknown.

Diagnostic characters: See key

Type Material: Holotype (male), Brazil, Amazonas state, Manaus, Adolpho Ducke Forest Reserve, Km 26 of the AM010 Highway, CDC light trap (height of 15 meters in the forest canopy), 24/i/1978, coll. Jorge Arias, Katia Arias and João Vidal. Paratypes (two males), same data as holotype, except for the collection date (27/xi/1977) of one of the paratypes. The type material was deposited in the Invertebrate Collection of the Instituto Nacional de Pesquisas da Amazônia (INPA), Manaus, Amazonas, Brazil, with voucher numbers: INPA-DIP 001945 (holotype) and INPA-DIP 001946 and INPA-DIP 001947 (paratypes).

The new taxon was registered in Zoobank as B5A7277A2FD5-4F5B-8CF5-1623473FD805.

Etymology: Pintomyia (Pifanomyia) duckei makes reference to Adolpho Ducke Forest Reserve, where the specimens were collected. This preserved area of 100 sq.km, used for research activities, is owned by Instituto Nacional de Pesquisas da Amazônia (INPA).

\section{DISCUSSION}

According to the classification system of the subfamily Phlebotominae with the phylogenetic approach of Galati (2003; 2017), Pintomyia (Pifanomyia) duckei sp. n., belongs to the tribe Phlebotomini Rondani 1840, subtribe Lutzomyiina Abonnenc and Leger 1976, due to the presence of upper proepimeral and anepisternal setae; $1^{\text {st }}$ flagellomere (FI) with internal ascoid at a more basal level than the external one, presence of ventro-cervical sensillae and pilosity in the frontal region of the catepisternum; PII palpal segment greater than PIV; and Newstead's sensilla disperses in the internal face median of PIII. It belongs to the genus Pintomyia Costa Lima, 1932 due to the presence of the flagellomere (FI), larger than half the length of the head; gonocoxite with longitudinally sclerosed band on internal basal face; simple paramere, without pointed preapical protuberance of the ventral margin; epandrial lobe, rounded subcylindrical apex, narrower than the gonocoxite, and gonostylus with subapical spiniform seta. Posterior femur with spines and gonostylus with four spines of similar size and width are diagnostic characters for the subgenus Pintomyia sensu stricto. Despite the absence of the legs in the specimens of the new taxon, we could identify the gonostylus with two stout and long spines (one apical and one external subapical), and one slender and short spine on the internal median face, which characterize the Serrana Series Barretto, 1962, of the subgenus Pifanomyia Ortiz and Scorza, 1963.

The Serrana Series of the subgenus Pifanomyia is currently composed of 13 species. Of these, seven species [Pi. guilvardae (Le Pont, Martinez, Torrez-Espejo and Dujardin), Pi. odax (Fairchild and Hertig), Pi. oresbia (Fairchild and Hertig), Pi. ottolinai (Ortiz and Scorza), Pi. piedraferroi (León), Pi. robusta (Galati, Cáceres and Le Pont) and Pi. serrana (Damasceno and Arouck)] have males possessing gonostylus with two stout spines (one apical and another external subapical), one small and very thin (or atrophied) spine on the basal half of the inner surface, and one subterminal spiniform seta. In the other six species [Pi. boliviana (Velasco and Trapido), Pi. christophei (Fairchild and Trapido), Pi. diazi (Gonzales and Garcia), Pi. novoae (Gonzales and Garcia), Pi. orestes (Fairchild and Trapido) and Pi. torresi (Le Pont and Desjeux)] the gonostylus has three stout spines (the internal spine being equivalent in size and caliber to the external ones), beside the subterminal spiniform seta. As for the number, caliber and arrangement of the spines in the gonostylus, Pi. (Pif.) duckei sp. n. has close affinity with the first seven species. It differs from all 13 species by the presence of some peculiar characters, such as the dilated (or inflated) gonocoxite with length less than twice the width; dilated or inflated paramere, with slender apex and slightly convex dorsal margin, whith length surpassing the apex of the epandrial lobe. With this new taxon, the Serrana Series is now composed of 14 species, according to the identification key below.

Regarding the two anomalous specimens, the most evident morphological alterations refer to the tufts of basal setae of gonocoxites. In one of them (Figure 2a, Figure 2b), one of the gonocoxites has six setae rowed in the basal tuft, therefore, with a supernumerary seta; while the other gonocoxite has basal tufts with two parallel longitudinal rows with five and six setae, respectively, characterizing a bilateral asymmetric anomaly (Sanguinette et al. 2013). Other morphological alterations were the morphometry of the head, same palpal formula as the holotype, but length of the 5th palpal segment (PV) less than the sum of PI+PII+PIII; and alpha length of the wing 
much greater than the gamma length. In the other anomalous specimen (Figure 2c, Figure 2d), one gonocoxites has five setae, while the other has six setae (one supernumerary seta) in the basal tufts, characterizing a unilateral anomaly; and the alpha length of the wing is also greater than the gamma length.

Structural deformations are frequent in phlebotomine sandflies, occurring mainly in the terminalia of male specimens, unilaterally or bilaterally, with differences in number, arrangement, size and appearance of permanent setae in gonocoxites, parameres and epandrial lobe (Sherlock 1963; Marcondes 1999; Ximenes et al. 2002; Costa 2012; Sanguinette et al. 2013; Alves et al. 2015). Since the first record of anomalies in phlebotomine made by Newstead (1914) for Sergentomyia minuta (Rondani), several cases of anomalies have been reported in several parts of the world (Newstead and Sinton 1921; Dampf 1945; Abonnenc et al. 1971; Feliciangeli et al. 1985; Kassen et al. 1988; Ximenes et al. 2002; Guernaoui et al. 2010; Costa et al. 2012; Deboín et al. 2015). Despite this, the origin and significance of the anomalies present in phlebotomine sandflies are not yet well understood. It is suspected that they may be the result of injury during ontogeny, of genetic origin (mutational), of pathological nature, or induced by environmental pressure (Feliciangeli et al. 1985; Kassen $e t$ al. 1988; Costa et al. 2012). Anomalies found in males of Phlebotomus papatasi Scopoli, for example, were associated with disturbed environments from where they have been collected (Guernaoui et al. 2010).

The biological significance of these malformations is also unknown. Possibly, some of them may not influence

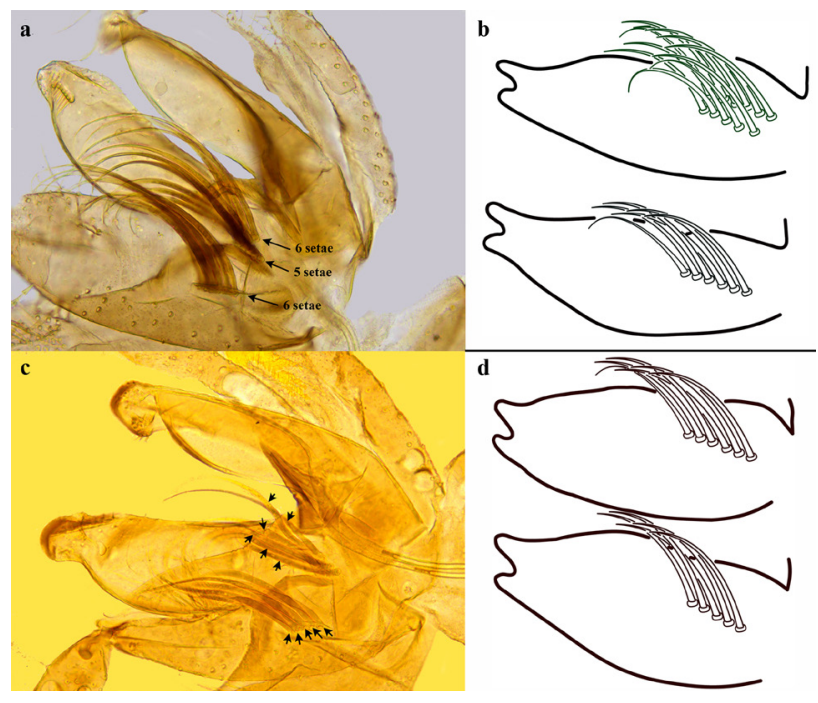

Figure 2. Anomalous males of Pintomyia (Pifanomyia) duckeisp. n. Oliveira, Alencar \& Freitas: (a,b) Bilateral asymmetric anomaly. One of the gonocoxites with six setae rowed in the basal tuft. Other gonocoxite with two basal tufts of five and six setae rowed indicated by arrows, ( $b=S c h e m e) ;(c, d)$ Unilateral anomaly. Gonocoxites with five and six setae in basal tufts indicated by arrows, ( $\mathrm{d}=\mathrm{Scheme}$ ). This figure is in color in the electronic version. the behavior of the individual, while others may impede its development (Abonnenc et al. 1971; Florín et al. 2010). Regardless of its origin and significance, the records of new anomalies are of fundamental importance, because the description of new species through anomalous specimens can lead to serious systematic inconformities with the diagnostic characters of the taxonomic groups (Andrade-Filho et al. 2004).

\section{Identification key to species of the subgenus Pifanomyia - Serrana Series (adapted from Galati, 2017) (based exclusively on male characters)}

1 Gonostylus with two stout spines (one apical and one external subapical), and one very thin or atrophied on the inner surface of the basal half of the structure .2

Gonostylus with three stout spines implanted as in the previous alternative, but with the internal spine of size and caliber equivalent to the external one . .9

2(1) Gonocoxite with one multi-branched basal seta Pi. (Pif.) piedraferroi ${ }^{1}$

Gonocoxtie with one basal group (tuft) of three or more simple setae .3

3(2) Gonocoxite tuft with straightsetae........................4

Gonocoxite tuft with curved setae, and of apexes directed toward the gonocoxite ........................................

4(3) Gonocoxite tuft with four or five loose setae implanted in a single row, some reaching the apex of the paramere .Pi. (Pif.) oresbia

Gonocoxite tuft with three or four grouped setae, all of uniform size, reaching the middle of the paramere ...Pi. (Pif.) ottolinai

5(3) Gonocoxite tuft with five setae .......................6

Gonocoxite tuft with six or seven setae .........Pi. (Pif.) odax

6(5) Gonocoxite dilated (or inflated), length less than twice the width. Paramere dilated with slender apex and slightly convex dorsal margin, length surpasses the apex of the epandrial lobe ..Pi. (Pif.) duckei sp. n.

Other character combinations .7

7(6) Gonocoxite tuft with long setae, surpassing apex of paramere ................................ Pi.(Pif.) guilvardae

Gonocoxite tuft with short setae, not reaching the apex of paramere

1 Young and Duncan (1994 - p. 243, Figure 105) studied the holotype and verified the presence of four spines on the gonostylus rather than three as ilustrated by León (1971). 
8(7) Paramere: length of the apical area, covered with setae, less or equal to twice its width; dorso-basal margin with marked concavity. Gonocoxite tuft with one of the setae not aligned with the others

Pi. (Pif.) robusta

Paramere: length of the apical area, covered with setae, greater than 2.5 times its width; dorsal margin practically straight. Gonocoxite tuft with strictly lined setae ....... Pi. (Pif.) serrana

9(1) Paramere simple 10

Paramere bilobed 13

10(9) Mesonotum pale

Mesonotum dark

11(10) Gonocoxite tuft with 20 or more simple and straight setae, implanted on a small tubercle . Pi. (Pif.) christophei

Gonocoxite tuft with four or five simple and curved setae, implanted directly on the surface of the gonocoxite.... Pi. (Pif.) orestes

12(10) Gonocoxite with one basal tuft composed of 10 to 12 setae Pi. (Pif.) diazi

Gonocoxite with two tufts of setae in medium position ...... Pi. (Pif.) novoae

13(9) Length of ventral lobe of the paramere equivalent to the dorsal; interlobular region with three to five setae Pi. (Pif.) torresi

Length of ventral lobe of the paramere evidently much shorter than the dorsal one; interlobular region with 10 or more setae Pi. (Pif.) boliviana

\section{CONCLUSIONS}

Pintomyia (Pifanomyia) duckei sp. n. belongs to the Serrana Series and subgenus Pifanomyia. In this Series, this species has greater affinity with the species with males possessing gonostylus with two stout spines, one small and very thin spine on its basal half of the inner surface, and one subterminal spiniform seta. Pintomyia (Pif.) duckei sp. n. differs from these species by having dilated (or inflated) gonocoxite with length less than twice the width; dilated or inflated paramere, with slender apex and slightly convex dorsal margin, with length surpassing the apex of the epandrial lobe. The paratypes present morphological anomalies, which appear to be frequent in phlebotomine sandflies, and their records are important for phlebotomine taxonomy, to avoid mistakes in specific identification, and the erroneous description of new species.

\section{ACKNOWLEDGMENTS}

We express our sincere thanks to the technical draftsman Mr. Artêmio Coelho da Silva for the illustrations, to the laboratory technicians, Mr. Francisco Lima Santos and Maria Ivonei Carvalho Albuquerque for their assistance in the collection of sandflies and providing the bibliographical references, and to Mr. Anibrata Pal and Ahana Maitra for the corrections of the English text.

\section{REFERENCES}

Abonnenc, E.; Leger, N. 1976. Sur une classification rationellee des Dipteres Phlebotomidae. Cahiers de l'Office de la Recherche Scientifique et Technique Outre-Mer. Entomologie Medicale et Parasitologie, 14: 69-78.

Abonnenc, E.; Poinsot, S.; Rioux, J.A. 1971. Tératologie des Phlébotomes (Diptera: Psychodidae) Révision et nouvelles observations. Cahiers de l'Office de la Recherche Scientifique et Technique Outre-Mer. Entomologie Medicale et Parasitologie, 3: 307-316.

Andrade-Filho, J.D.; Carvalho, G.M.L.; Saraiva, L.; Falcão, A.L. 2004. Bilateral anomaly in the style of Micropygomyia schreiberi (Martins, Falcão and Silva) (Diptera, Psychodidae). Revista Brasileira de Entomologia, 48: 583-585.

Alves, V.R.; Freitas, R.A. 2015. Description of a new species of Psathyromyia Barretto (Diptera, Psychodidae, Phlebotominae) from Amazonas state, Brazil. Revista Brasileira de Entomologia, 59: 205-209.

Barretto, M.P. 1962. Novos subgêneros de Lutzomyia França, 1924 (Diptera. Psychodidae. Subfamília Phlebotominae). Revista do Instituto de Medicina Tropical de São Paulo, 4: 91-100.

Costa Lima, A. 1932. Sobre os phlebotomos americanos (Diptera: Psychodidae). Memórias do Instituto Oswaldo Cruz, 26: 15-69.

Costa, P.L.; Silva, F.J.; Andrade-Filho, J.D.; Shaw, J.J.; BrandãoFilho, S.P. 2012. Bilateral Anomaly in Evandromyia evandroi (Diptera: Psychodidae: Phlebotominae) cap-tured in Vicência municipality, northern rainforest region of Pernambuco state, Brazil. Journal of the American Mosquito Control Association, 28: 128-130.

Cumming, J.M.; Wood, D.M. 2009. Adult morphology and terminology. In: Brown, B.V.; Borkent, A.; Cumming, J.M.; Wood, D.M.; Woodley, N.E.; Zumbado, M.A. (Eds.), Manual of the Central American Diptera, vol. I. NRC ResearchPress, Ottawa, p.9-50.

Dampf, A. 1945. Un caso de asimetria en el hipopigio masculino de Phlebotomus migonei Franca, 1920 (Inst. Dipt.). Boletin de Entomologia Venezuelana, 4: 153-159.

Daboín, Y.M.; Oviedo-Araújo, M.; González-Pérez, A.; SuárezHernández, J.; Sandoval, C.M.; Cazorla, D. 2015. Anomalías morfológicas en los dientes del cibario de Lutzomyia evansi (Diptera: Psychodidae) en el estado Trujillo, Venezuela. Biomédica, 35: 269-273.

Feliciangeli, M.D.; Ordoñez, R.; Aguilar, C.M. 1985. Morphological anomalies in phlebotomine sand flies are reviewed and update with abnormalities observed in Venezuela on the species $L$. trinidadensis, L. shannoni, L. lichyi and L. gomezi, and the description of a teratological unidentified male. Acta Amazônica, 15: 157-166. 
Florín, D.A.; Lawyer, P.; Rowton, R.; Schultz, G.; Wilkerson, R.; Davies, S.J.; Lipnick, R.; Keep, L. 2010. Morphological Anomalies in Two Lutzomyia (Psathyromyia) shannoni (Diptera: Psychodidae: Phlebotominae) Specimens Collected from Fort Rucker, Alabama, and Fort Campbell, Kentucky. Journal of Medical Entomology, 47: 952-956.

Galati, E.A.B. 2003. Morfologia e Taxonomia. In: Rangel, E.F.; Lainso, R. (Ed.). Flebotomineos do Brasil. Editora Fiocruz, Rio de Janeiro, p.23-51.

Galati, E.A.B. 2017. Phlebotominae (Diptera, Psychodidae). Classificação, morfologia, terminologia e identificação de adultos [apostila], Vol. I. Bioecologia e Identificaçâo de Phlebotominae, São Paulo: USP, 130p.

Galati, E.A.B.; Galvis-Ovallos, F.; Lawyer, P.; Léger, N.; Depaquit, J. 2017. An illustrated guide for characters and terminology used in descriptions of Phlebotominae (Diptera, Psychodidae). Parasite, 24: 26.

Guernaoui, S.; Ramaoui, K.; Rahola, N.; Barnabe, C.; Sereno, D.; Boumezzough, A. 2010. Malformations of the genitalia in male Phlebotomus papatasi (Scopoli) (Diptera: Psychodidae). Journal of Vector Ecology, 35: 13-19.

Kassem, H.; Sattar, S.A.; Shehata, M.G.; Sawaf, B. 1988. Abnormalities in the sand fly Phlebotomus papatasi Scopoli (Diptera: Psychodidae) of Egypt. Journal of the Egyptian Public Health Association, 63: 209-213.

Leon J.R. 1971. Contribucion at estudio de los Phlebotomus (Diptera: Psychodidae). Phlebotomus del grupo anthophorus en Guatemala. Revista del Colegio Médico de Guatemala, 22: 187-193.

Marcondes, C.B. 1999. Anomalies of Lutzomyia intermedia (Lutz e Neiva, 1912) (Diptera, Psychodidae, Phlebotominae). Memórias do Instituto Oswaldo Cruz, 94: 365-366.

Marcondes, C.B. 2007. A proposal of generic and subgeneric abreviations for phlebotomine sandiflies (Diptera: Psychodidae: Phlebotominae) of the world. Entomology News, 118: 351-356.
Newstead, R. 1914. Notes on Phlebotomus, with description of new species. Part II. Bulletin of Entomological Research, 5: 179-192.

Newstead R.; Sinton, J.A. 1921. On collection of pappataci flies (Phlebotomus) from India. Annals of Tropical Medicine and Parasitology, 15: 103-106.

Ortiz, I.; Scorza, J.V. 1963. Notas biologicas y taxonomicas sobre algunos Phlebotominae (Diptera, Psychodidae) de Rancho Grande. Venezuela. Acta Biologica Venezuelica, 3: 841-381.

Rondani, C. 1840. Sopra una specie di insetto dittero. Memoria prima per servire alla Ditterologia Italiana $n^{\circ} 1$, Donati, Parma, 16p.

Sherlock, I.A. 1963. Variability of the genitália of "Phlebotomus bahiensis" (Diptera, Psychodidae). Revista Brasileira de Biologia, 23: 49-53.

Sanguinette, C.C.; Faustino, J.X.; Serra e Meira, P.C.L.; Botelho, H.A.; Carvalho, G.M.L.; Gontijo, C.M.F.; Andrade Filho, J.D. 2013. Anomalies in the Sand Fly Lutzomyia longipalpis (Diptera: Psychodidae) in Brazil. Journal of the American Mosquito Control Association, 29: 54-58.

Sudia, W.D.; Chamberlain, R.W. 1962. Battery-operates light trap, na improved model. Mosquito News, 22: 126-129.

Theodor, O. 1965. On the classification of American Phlebotominae. Journal of Medical Entomology, 2: 171-197.

Ximenes, M.F.F.M.; Castellón, E.G.; Freitas, R.A. 2002. Morphological genitalic anomaly in Lutzomyia longipalpis sensu lato (Lutz and Neiva, 1912) collected in the State of Rio Grande do Norte, Brazil. Entomotropica,17: 183-184.

RECEIVED: $24 / 11 / 2017$

ACCEPTED: 25/04/2018

ASSOCIATE EDITOR: Pitágoras da Conceição Bispo 